\title{
Reduction of cardiac iron overload by optimising iron chelation therapy in transfusion dependent thalassaemia using cardiac T2* MRI: a quality improvement project from Pakistan
}

Shabneez Hussain ำ ${ }^{1}$ Zahra Hoodbhoy, ${ }^{2}$ Fatima Ali, $^{2}$ Erum Hasan, ${ }^{3}$ Najveen Alvi, ${ }^{2}$ Aijaz Hussain, ${ }^{1}$ Khajista Ishrat, ${ }^{1}$ Zia Ur Rahman, ${ }^{1}$ Azizuddin Qamruddin, ${ }^{1}$ Azra Parvin, Babar S Hasan² Sindh, Pakistan

${ }^{2}$ Department of Pediatrics and Child Health, The Aga Khan University and Hospital, Karachi, Sindh, Pakistan

${ }^{3}$ Kashif Iqbal Thalassaemia Care Centre, Karachi, Sindh, Pakistan

\section{Correspondence to}

Dr Shabneez Hussain, Fatimid

Foundation, Karachi, Sindh

Pakistan;

shabneez.haem@gmail.com

Published Online First

29 September 2020
Fatimid Foundation, Karachi,

\begin{abstract}
Objectives Cardiac T2* MRI (T2*CMR), for accurate estimation of myocardial siderosis, was introduced as part of a QI collaborative to optimise chelation therapy in order to improve cardiac morbidity in transfusion dependent thalassaemia (TDT) patients. We report the impact of this QI initiative from two thalassaemia centres from this collaborative.
\end{abstract}

Design and setting A key driver based quality initiative was implemented to improve chelation in TDT patients registered at these two centres in Karachi, Pakistan. Protocol optimisation and compliance to treatment through training, communication and feedback were used as the drivers for QI intervention. Preintervention variables (demographics, chelation history, $\mathrm{T} 2{ }^{*} \mathrm{CMR}$, echocardiography and holters) were collected from January 2015 to December 2016) and compared with variables in the post implementation phase (January to December 2019). A standardised adverse event severity for chelators and its management was devised for safe drug therapy as well as ensuring compliance to the regimen. Preintervention and postintervention variables were compared using nonparametric test. P value $<0.05$ was statistically significant. Results 100 patients with TDT, median age 17 (9-34) years, were included. An increase or stabilisation of $\mathrm{T} 2{ }^{*} \mathrm{CMR}$ was documented in $82 \%$ patients in the postintervention phase especially in patients with severe myocardial iron overload ( 5.5 vs 5.3 ms, p $<0.01)$. Significantly fewer patients had abnormal echocardiographic findings ( $3.5 \%$ vs $26 \%, p<0.05)$ in the postintervention versus preintervention period. Conclusion This QI initiative improved the chelation therapy leading to improved cardiac status in TDT patients at the participating centres.

Check for updates

(C) Author(s) (or their employer(s)) 2020. No commercial re-use. See rights and permissions. Published by BMJ.

To cite: Hussain $\mathrm{S}$

Hoodbhoy Z, Ali F, et al.

Arch Dis Child

2020;105:1041-1048

\section{INTRODUCTION}

Recurrent transfusions are the mainstay of therapy in transfusion dependent thalassaemia (TDT) but leads to significant hepatic, endocrine and cardiac iron overload over time if chelation is inadequate. Cardiac iron overload in inadequately chelated patients with TDT develops as early as 5.5 years, ${ }^{12}$ whereas detectable cardiac iron overload has been reported in $24 \%-36 \%$ of well chelated patients at 9.5-18 years of age. ${ }^{3}$ Cardiac iron overload may
What is already known on this topic?

- Transfusion dependent thalassaemia (TDT) patients in resource constrained settings are known to have severe cardiac disease on cardiac T2* MRI.

- QI based collaborative using a key driver diagram approach is shown to improve outcomes in complex diseases.

- A quality improvement collaborative has been established in Pakistan to improve morbidity and mortality in TDT patients.

\section{What this study adds?}

- Demonstrates effectiveness of a QI initiative focused on process re-engineering using existing resources to manage transfusion dependent thalassaemia (TDT) in a low resource setting.

- Devised and assessed the clinical applicability of a novel chelation drug related adverse events severity level definition and its standard management in this population to ensure improved compliance to the prescribed chelation regimens.

- Demonstrate the impact of standardised care in improving patient management and their compliance in chronic diseases.

be reversible through early detection and optimal intensive chelation. ${ }^{4}$ Several factors like access to care ${ }^{5}$ unavailability of accurate cardiac iron measurements (such as cardiac $\mathrm{T} 2 *$ magnetic resonance imaging (T2*CMR)) and chelation agents, ${ }^{5}$ poor chelation compliance due to patient and physician discomfort with drug related adverse events (AE), ${ }^{67}$ and lack of standardised treatment protocols ${ }^{8}$ contribute towards poor chelation of patients with TDT in low middle income countries (LMICs) like Pakistan. A preliminary analysis from Pakistan demonstrated that $50 \%$ of patients being treated at a tertiary care centre using ferritin as a marker for iron load and a way to direct chelation management, had severe myocardial iron load on 
T2*CMR ( $<10 \mathrm{~ms})$, while $70 \%$ of the patients were in New York Heart Association (NYHA) functional class II or worse which correlated with decreasing T2*CMR value. ${ }^{9}$

In Pakistan, patients with TDT are treated by various nongovernmental organisations or thalassaemia treatment centres and thus there is significant practice variation in assessment and management of myocardial iron load. The impact of quality improvement (QI) initiative using a key driver diagram (KDD) approach, done individually or as part of a collaborative, in improving clinical outcomes is very well established especially in congenital heart disease. ${ }^{10-12}$ A continuous QI process coupled with Plan, Do, Study, Act (PDSA) cycle makes such an intervention highly effective. ${ }^{12} 13$ A similar QI collaborative for care of patients with TDT was established in Pakistan with the goal to reduce mortality and morbidity in TDT. ${ }^{14} \mathrm{~A}$ main KDD was previously created with the aim to reduce cardiac and endocrine organ iron overload related mortality and morbidity, by specific interventions (both cardiac and endocrine) in patients with TDT. ${ }^{14} 15$ This report focuses on a QI initiative to specifically decrease cardiac iron siderosis and subsequently its related morbidity at two out of the four centres which were part of this collaborative.

\section{MATERIALS AND METHODS}

As part of the collaborative, ${ }^{14}$ a QI initiative specifically focused on reducing cardiac siderosis and its related morbidity, was designed at two of the four collaborating not-for-profit thalassaemia treatment centres (Fatimid Foundation, Karachi (FFK) and Kashif Iqbal Thalassaemia Care Centre (KITCC)). Employing a PDSA cycle methodology and KDD approach, the QI initiative was executed from January 2015 to December 2019. Preintervention data was collected from January 2015 to December 2016 and compared with postintervention data from January 2019 to December 2019 for both process and outcome metric (as described in the section on "outcome and process metrics”). Interventions were implemented with 6-monthly informal process evaluations from January 2017 to December 2018. Comparison of data and final decision of the PDSA cycle to repeat i.e. continue or change the strategies were made in January 2020. Decision to collect the data and analyse both the process and outcome metric (first PDSA cycle ie, after 2 years of beginning of the initiative) was due to the limitation of the T2*CMR centre (The Aga Khan University and Hospital $(\mathrm{AKUH})$ ) of performing only $10 \mathrm{~T} 2 * \mathrm{CMRs} / \mathrm{month}$. Additionally, significant behaviour change strategies needed to be employed (education, reinforcement etc) to bring about standardisation of chelation, medication compliance and understanding and running a PDSA cycle (see online supplemental material 1 for additional details).

\section{Identification of key drivers}

The following factors that led to poor management of cardiac siderosis were identified (refer to online supplemental text for details).
AIM KEY DRIVERS

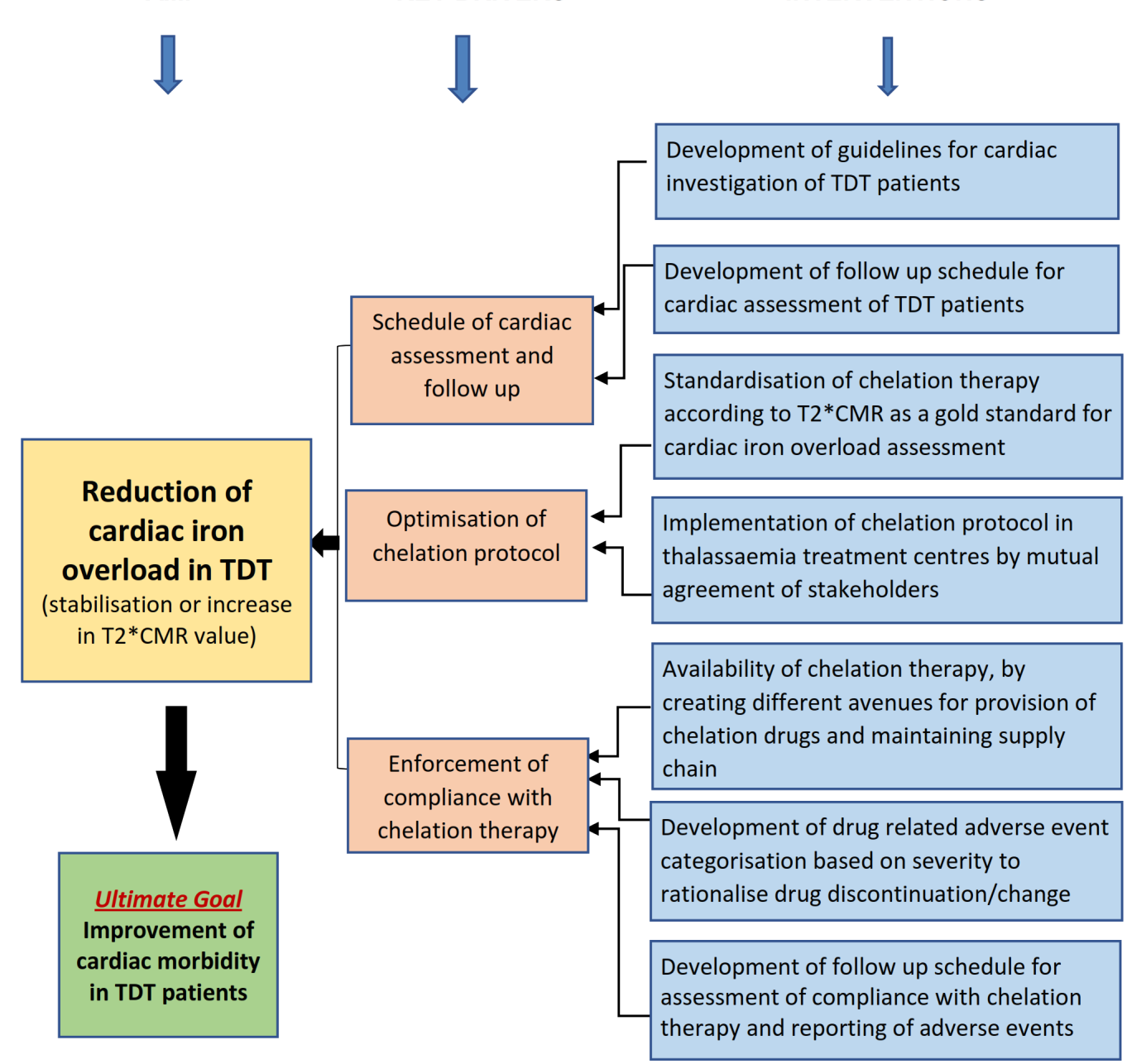

Figure 1 Key driver diagram. T2* CMR, cardiac T2* magnetic resonance imaging; TDT, transfusion dependent thalassaemia. 
Table 1 Details of specific interventions according to key driver diagram

\begin{tabular}{|c|c|c|}
\hline Key drivers & Interventions & Outcome and process metrics \\
\hline $\begin{array}{l}\text { Schedule for cardiac } \\
\text { assessment and } \\
\text { follow-up }\end{array}$ & 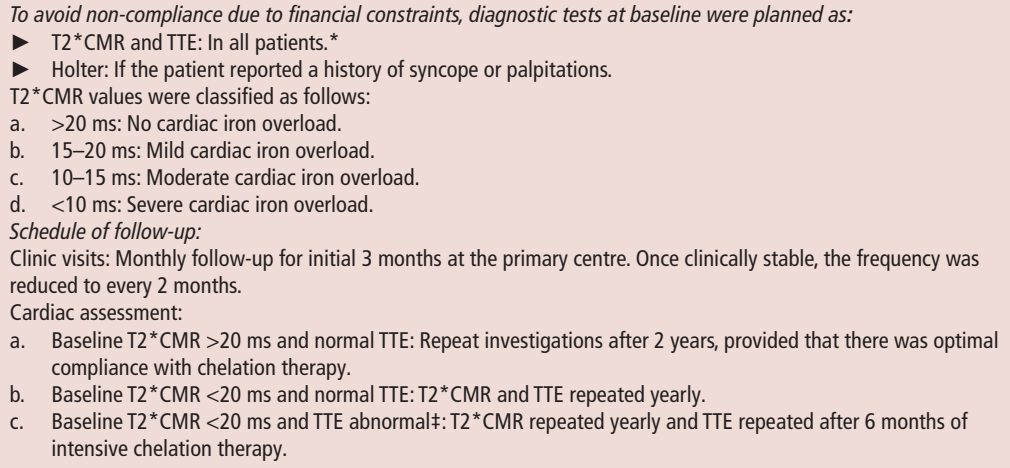 & $\begin{array}{l}\text { Process metric } \\
\text { Adequacy of cardiac assessment and follow-up according } \\
\text { to guidelines. } \\
\text { Outcome metrict } \\
\text { Percentage of patients with increase or stabilisation of } \\
\mathrm{T}^{*} \mathrm{CMR} \text { value after intervention. } \\
\text { Increase in the cumulative median } \mathrm{T} 2^{*} \mathrm{CMR} \text { of the patient } \\
\text { cohort. } \\
\text { Percentage of patients with improvement in cardiac } \\
\text { dysfunction on echocardiography. }\end{array}$ \\
\hline $\begin{array}{l}\text { Optimisation of } \\
\text { chelation protocol }\end{array}$ & 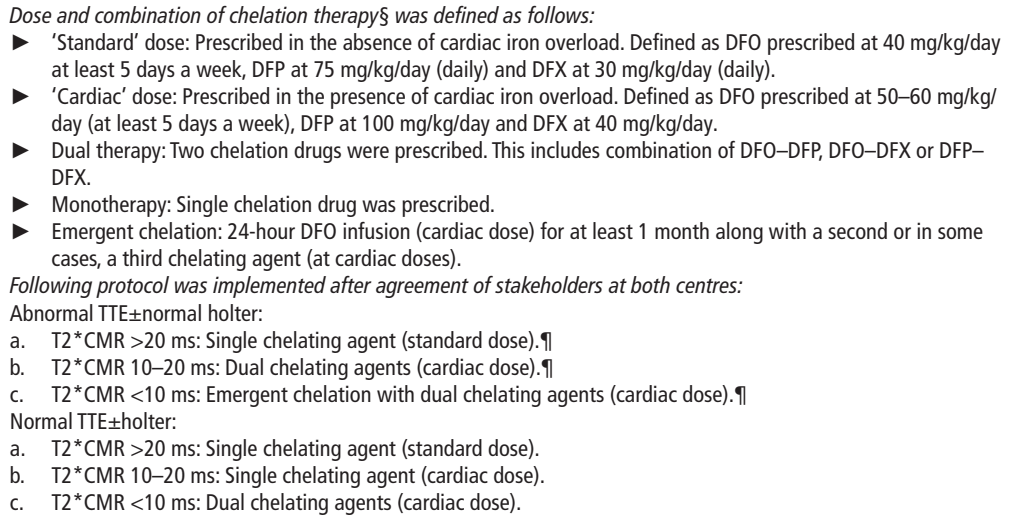 & $\begin{array}{l}\text { Process metric } \\
\quad \text { Standardisation of chelation therapy. }\end{array}$ \\
\hline $\begin{array}{l}\text { Enforcement of } \\
\text { compliance with } \\
\text { chelation therapy }\end{array}$ & $\begin{array}{l}\text { Compliance check of chelation therapy: } \\
\text { Since there were no drug levels to assess compliance with chelation therapy, a detailed medication history by the } \\
\text { haematologist was performed at every follow-up visit. Compliance was described as follows: } \\
\text { Optimal compliance: When chelation drugs were taken as prescribed with drug missed for not more than } 7 \\
\text { days between each } 2 \text {-monthly follow-up. } \\
\text { Partial compliance: When chelation drug was missed for }>7 \text { but }<15 \text { days between the } 2 \text {-monthly follow-ups or } \\
\text { taking } 50 \% \text { dose of monotherapy prescribed or taking one drug in the prescribed combination therapy. } \\
\text { Non-compliance: When drug gap exceeded } 15 \text { days and/or not on any chelation therapy. } \\
\text { Other strategies: } \\
\text { Awareness: Patients and families were educated about benefits of optimal chelation therapy during clinic visits. } \\
\text { Availability of drugs: Drugs were made available at the participating thalassaemia centres or by referral to } \\
\text { other thalassaemia centres and/or government hospitals where chelation medications were offered free of } \\
\text { cost. } \\
\text { Standardisation of chelation drug AE severity description and its management: A novel chelation medication AE } \\
\text { severity description was developed and categorised into five severity levels to standardise drug continuation/ } \\
\text { discontinuation/change by both patients and healthcare professionals (details in table } 2 \text { ). }\end{array}$ & $\begin{array}{l}\text { Process metric } \\
\text { Compliance with recommended chelation therapy. } \\
\text { Reporting of AE severity levels. } \\
\text { or continuation of chelation therapy after introduction of } \\
\text { AE severity description. } \\
\text { Percentage of severity level 3-5 AE on intensification } \\
\text { therapy. }\end{array}$ \\
\hline
\end{tabular}

${ }^{*} \mathrm{~T} 2{ }^{*} \mathrm{CMR}$ was not performed in patients presenting with acute heart failure requiring emergent admission in hospital as breath holding for MRI was not possible in these patients. T2 ${ }^{*} \mathrm{CMR}$ was obtained once patient was stabilised with emergent chelation for at least 2 weeks.

tOutcome metric was meant to measure the effectiveness of the complete initiative thus demonstrating the cumulative effect of all the key drivers.

$\ddagger$ Abnormal TTE is defined as systolic (left ventricular ejection fraction $<56 \%$ and/or age based low peak systolic left ventricular global longitudinal strain value) and/or diastolic dysfunction.

$\S$ In the absence of iron overload or out of proportion cardiac dysfunction not explained by iron load, evaluate for other causes of myocardial dysfunction that is, viral (hepatitis B and C, HIV etc) myocarditis, electrolyte (eg, profound hypocalcaemia) or vitamin (eg, Vitamin D or B deficiency etc), endocrinological (eg, hypothyroidism, hypocalcaemia etc) related cardiac dysfunction.

IDFO was infused daily by a subcutaneous infusion pump for 8-12 hours or in hospital over 24 hours (if patient had signs of heart failure or significant cardiac dysfunction on TTE with moderate to severe cardiac siderosis on T2*CMR), DFP was prescribed daily in three divided doses and DFX was given in a one time per day dosing schedule. All oral chelators were prescribed after meals.

$\mathrm{AE}$, adverse event; DFO, deferoxamine; DFP, deferiprone; DFX, deferasirox; T2*CMR, cardiac T2* magnetic resonance imaging; TTE, transthoracic echocardiography.

1. Assessment: There was lack of standardisation in cardiac assessment of patients with TDT.

2. Management: Chelation therapy was guided by serum ferritin level (a poor marker of myocardial iron load) rather than the gold standard $\mathrm{T} 2 * \mathrm{CMR}$ value.

3. AE: Discontinuation of drugs was common even due to minor drug related $\mathrm{AE}$ or poor patient counselling by physicians, leading to inconsistent chelation.

Three key drivers and their respective interventions were identified to address these issues (figure 1 and table 1).

\section{Outcome and process metrics}

Two metrics were used to assess the performance of the QI initiative that is, outcome and process metrics. Outcome metrics for this initiative were defined as a decrease in cardiac morbidity measured by percentage of patients with an increase or stabilisation of $\mathrm{T} 2 * \mathrm{CMR}$, increase in median $\mathrm{T} 2 * \mathrm{CMR}$ of the cumulative cohort and percentage of patients with improvement in cardiac dysfunction (as evaluated by echocardiogram) in the postintervention phase (table 1 ). Process metrics were used to assess the effectiveness of the interventions aligned with the key drivers. Process was evaluated every 6 months from the beginning of the intervention and continuous reinforcement of physician and patients to standardise evaluation and management of cardiac siderosis was done at the same time. For this initiative process metrics were defined as compliance with cardiac assessment and its follow-up, standardisation of chelation therapy, compliance with chelation therapy, reporting of AE severity level (table 2), percentage of patients with inappropriate discontinuation/continuation of chelation therapy after AE reporting and 
Table 2 Details of adverse event (AE) severity level and its management*

\begin{tabular}{|c|c|c|c|}
\hline Severity level & Definition & Intervention & Examples \\
\hline 1 -minimal & No harm; no change in condition. & $\begin{array}{l}\text { Resolves with proper counselling. } \\
\text { Does not require any change in dose or } \\
\text { generic. }\end{array}$ & Mild nausea with DFP or DFX. \\
\hline 2-minor & $\begin{array}{l}\text { Transient change in condition. } \\
\text { Not life-threatening. } \\
\text { Condition returns to baseline with } \\
\text { interventions. } \\
\text { Not directly related to the drug. }\end{array}$ & Requires temporarily holding the medication. & $\begin{array}{l}\text { Viral fever on DFO. } \\
\text { Thrombocytopenia due to infection while on DFP. } \\
\text { Raised serum transaminases due to viral hepatitis. } \\
\text { Mild rash while on DFX. }\end{array}$ \\
\hline 3-moderate & $\begin{array}{l}\text { Change in condition not life threatening. } \\
\text { Condition returns to baseline once drug } \\
\text { is stopped. }\end{array}$ & $\begin{array}{l}\text { Requires intervention such as stopping or } \\
\text { switching the drug. }\end{array}$ & $\begin{array}{l}\text { Infusion related local reactions on DFO. } \\
\text { Drug related neutropenia while on DFP. } \\
\text { Persistent nausea and vomiting with DFP or DFO. } \\
\text { Persistent rash with DFX. }\end{array}$ \\
\hline 4-major & $\begin{array}{l}\text { Toxic adverse effects on higher doses which } \\
\text { may lead to permanent disability or severe } \\
\text { illness that is, sepsis. }\end{array}$ & Permanent discontinuation of drug. & $\begin{array}{l}\text { Renal failure with DFX. } \\
\text { Ototoxicity or retinotoxity with DFO. } \\
\text { Febrile neutropenia and/or bleeding due to DFP. } \\
\text { Significant DFP related arthropathy leading to severe } \\
\text { disability. }\end{array}$ \\
\hline 5-catastrophic & \multicolumn{2}{|c|}{ Death or severe life altering disability (ie, becoming bed ridden) due to drug related AE. } & $\begin{array}{l}\text { Sepsis related to drug induced neutropenia leading to } \\
\text { mortality or significant morbidity like stroke, permanent end } \\
\text { organ damage, severe and permanent functional restriction. } \\
\text { Significant life-threatening bleeding due to drug related } \\
\text { thrombocytopenia. } \\
\text { Severe life-threatening acute liver failure. }\end{array}$ \\
\hline
\end{tabular}

*Patients who already had an AE for a specific drug prior to the study period were not considered for AE classification.

DFO, deferoxamine; DFP, deferiprone; DFX, deferasirox.

percentage of patients with AE severity level 3-5 on intensification therapy (table 1).

At baseline a detailed socio-demographic, transfusion, medication and clinical symptom history along with a physical examination was performed at the primary centre (FFK or KITCC). These patients were then referred for cardiac assessment to a paediatric cardiologist (BSH) at AKUH. Patients were then seen by a haematologist again at their primary centre for optimisation of chelation based on their cardiac evaluation (transthoracic echocardiography (TTE), T2* CMR and/or holter results) (table 1).

Being a part of the QI collaborative helped these centres in getting access to cardiac evaluation (specifically $\mathrm{T} 2{ }^{*} \mathrm{CMR}$ ), consultation and management of patients in acute heart failure requiring in-hospital treatment at no cost to the patient or to the centres. Additionally QI experts (BSH and FA) from AKUH (the organising centre in the collaborative) provided support in designing and implementation of the QI initiatives at FFK and KITCC.

\section{Statistical analysis}

All data were analysed using SPSS V.23.0. Data were expressed as medians (minimum (min), maximum $(\max ))$ for continuous variables and frequency (percentage) for categorical variables. The correlation of T2*CMR value with serum ferritin was performed using the Spearman rank correlation. Wilcoxon signed-rank test was performed for paired analysis of continuous variables while McNemar's test and Fisher's exact test were applied on categorical variables. Kruskal-Wallis test was used to compare three or more groups. $\mathrm{P}$ value $<0.05$ was considered statistically significant (for additional details refer to online supplemental material 1).

\section{RESULTS}

A total of 100 patients with TDT, being registered and managed at FFK and KITCC, with a median age of 17 (9-34) years and a female preponderance $(54 \%, n=54)$ were included in the analysis. At baseline cardiac assessment using TTE and T2*CMR was performed in all patients while holter monitoring was performed in $45 \%(\mathrm{n}=45)$ patients. Follow-up T2*CMR, TTE and holter were available for $55 \%(n=55), 58 \%(n=58)$ and $2 \%(n=1)$ patients respectively. Patients were regularly transfused every 2 weeks and maintained pretransfusion haemoglobin of 86 $(27-98) \mathrm{g} / \mathrm{L}$. Before intervention, majority of the patients were on partial chelation $50 \%(\mathrm{n}=50)$ while $11 \%(\mathrm{n}=11)$ received optimal chelation, 24\% $(\mathrm{n}=24)$ were underchelated and $15 \%$ $(n=15)$ not on any chelation therapy (also refer to online supplemental material 1 for additional results).

\section{Outcome metrics}

There was a trend towards an increase in the median (min, max) T2*CMR value of the cohort post initiative $10.1(2.1,45.8) \mathrm{ms}$ when compared to baseline $9.3(1.7,49) \mathrm{ms}(\mathrm{p}>0.05)$ (table 3$)$. A significant improvement in median T2* $\mathrm{CMR}$ value was seen in patients with severe (defined as $\mathrm{T} 2 * \mathrm{CMR}<10 \mathrm{~ms}$ ) cardiac iron overload in postintervention compared to preintervention period $(5.5$ vs $5.3 \mathrm{~ms}, \mathrm{p}<0.01)$ in the postintervention period (figure 2). Among those who had a repeat $\mathrm{T} 2 * \mathrm{CMR}, 82 \%$ patients had either an increase or maintenance of their cardiac T2*CMR value while only $18 \%(n=10)$ had a decrease in their $\mathrm{T} 2 * \mathrm{CMR}$ value compared to baseline. The trend of preintervention and postintervention T2* CMR for each patient is shown in online supplemental figure S1. Significantly fewer patients had abnormal echocardiographic findings $(3.5 \%$ vs $26 \%$, p $<0.05)$ in the postintervention versus preintervention period (table 3 ).

\section{Process metrics}

Standardisation of chelation increased significantly from $5 \%$ at baseline to $100 \%$ during the postintervention period $(\mathrm{p}<0.001)$. Ninety-five per cent of patients had a change in their chelation management $(89 \%$ had their chelation increased while $6 \%$ had a decrease in their dosing) (table 3, online supplemental table S1). Optimal compliance to chelation also significantly increased 
Table 3 Patient demographics, outcome and process metrics

\begin{tabular}{|c|c|c|c|}
\hline & Preintervention & Postintervention & $P$ value \\
\hline \multicolumn{4}{|l|}{ Baseline data } \\
\hline Median serum ferritin (min-max, $n g / m L$ ) & $4808(364-39500)$ & $4340(252-11000)$ & 0.004 \\
\hline Median $T 2{ }^{*} C M R$ value (min-max; $\left.m s\right)$ & $9.3(1.7-49)$ & $10.1(2.1-45.8)$ & 0.29 \\
\hline Echocardiography $(n, \%)$ & 100 & 58 & - \\
\hline Normal & $74(74)$ & $56(96.5)$ & \multirow{2}{*}{0.04} \\
\hline Abnormal & $26(26)$ & $2(3.5)$ & \\
\hline Systolic dysfunction only (on conventional and/or strain imaging) & $15(57.7)$ & $1(50)$ & \multirow{4}{*}{-} \\
\hline Diastolic dysfunction only & $6(23.1)$ & $1(50)$ & \\
\hline Systolic and diastolic dysfunction both & $3(11.5)$ & 0 & \\
\hline Pulmonary artery hypertension & $2(7.7)$ & 0 & \\
\hline Holter $(n, \%)$ & 45 & 1 & \\
\hline Normal & $17(38)$ & 0 & \\
\hline Abnormal & $28(62)$ & $1(100)$ & \\
\hline Atrial arrhythmias/tachycardia & $18(64)$ & $1(100)$ & \\
\hline Sustained or non-sustained ectopic atrial tachycardia & $7(39)$ & $1(100)$ & \\
\hline Atrial flutter & $1(5.5)$ & - & \\
\hline Premature atrial beats & $10(55.5)$ & - & \\
\hline Ventricular arrhythmias/tachycardia & $4(14)$ & - & \\
\hline Ventricular ectopy & $3(75)$ & - & \\
\hline Non-sustained ventricular tachycardia & $1(25)$ & - & \\
\hline Conduction defects & $4(14)$ & - & \\
\hline First degree atrioventricular block & $3(75)$ & - & - \\
\hline Right bundle branch block & $1(25)$ & - & \\
\hline Sinus tachycardia & $3(10.7)$ & - & \\
\hline Ectopic at pace low sinus rhythm & $9(32)$ & - & \\
\hline \multicolumn{4}{|l|}{ Outcome metric } \\
\hline $\mathrm{T} 2{ }^{*} \mathrm{CMR}$ value & 100 & 55 & \\
\hline$<10 \mathrm{~ms}$ & $51(51)$ & $30(55)$ & \\
\hline $10-15 \mathrm{~ms}$ & $17(17)$ & $11(20)$ & \\
\hline $15-20 \mathrm{~ms}$ & $5(5)$ & $3(5)$ & \\
\hline$>20 \mathrm{~ms}$ & $27(27)$ & $11(20)$ & \\
\hline Percentage of patients with postintervention increase or unchanged $\mathrm{T} 2{ }^{*} \mathrm{CMR}$ value & $82(82 \%)$ & & \\
\hline Percentage of patients with postintervention decrease in $\mathrm{T} 2^{*} \mathrm{CMR}$ value & $18(18 \%)$ & & \\
\hline \multicolumn{4}{|l|}{ Process metric } \\
\hline Cardiac assessment according to guidelines $(n, \%)$ & $0(0)$ & $100(100)$ & - \\
\hline Follow-up for cardiac assessment according to guidelines $(n, \%)$ & $0(0)$ & $55(55)$ & - \\
\hline Standardisation of chelation therapy according to T2* $\mathrm{CMR}(\mathrm{n}, \%)^{*}$ & $5(5)$ & $100(100)$ & 0.0001 \\
\hline \multicolumn{4}{|l|}{ Compliance with chelation therapy $(n, \%)$} \\
\hline Optimal compliance & $11(11)$ & $86(86) \dagger$ & \multirow{3}{*}{0.0001} \\
\hline Partial compliance & $50(50)$ & $13(13) \dagger$ & \\
\hline No compliance & $39(39)$ & $1(1)$ & \\
\hline AE reporting of chelation therapy $(n, \%)$ & $0(0)$ & $100(100)$ & - \\
\hline
\end{tabular}

${ }^{*}$ Chelation was intensified in $89 \%(n=89)$, reduced in $6 \%(n=6)$ and remained unchanged in $5 \%(n=5)$ patients after baseline T2*CMR. Cardiac doses were prescribed in $66 \%$ and in-hospital emergent chelation was indicated in $30 \%$ of patients.

tReasons for partial or non-compliance include non-affordability $(n=4,29 \%)$, personal reasons $(n=2,14 \%)$ and infusion related class 3 AEs secondary to DFO ( $n=8,57 \%)$. $\mathrm{AE}$, adverse events; $\mathrm{DFO}$, deferoxamine; max, maximum; min, minimum; $\mathrm{T}^{*} \mathrm{CMR}$, cardiac $\mathrm{T} 2 *$ magnetic resonance imaging.

in postintervention versus preintervention period $(86 \%$ vs $11 \%$, $\mathrm{p}<0.001)$.

Forty-eight per cent $(n=48 / 100)$ reported chelation related AE. No patient had severity level 4 or 5 AE. The majority who reported chelation related $\mathrm{AE}$ had severity level 3 (47.9\%, $n=23 / 48)$, followed by level $1(37.5 \%, n=18 / 48)$. Majority of these AEs were reported in patients who had an increase in their chelation dosing (online supplemental table S1). The most common $\mathrm{AE}$ was gastrointestinal intolerance $(32 \%, \mathrm{n}=26)$ seen mainly with deferiprone. All patients with AE were managed by counselling and none had an inappropriate discontinuation of chelation. During the postintervention period, 23\% $(n=23)$ patients had their medication appropriately changed or discontinued (online supplemental table S1). Thirteen patients (13\%) expired during the initiative with majority (53\%) related to cardiac aetiology. All of the expired patients were either partially compliant or non-compliant with their chelation during the preintervention period (table 4).

Serum ferritin of $>1000 \mathrm{ng} / \mathrm{mL}^{16}$ is considered as a marker of increased iron load and a concentration of $>2500 \mathrm{ng} / \mathrm{mL}$ signifies severe iron load. ${ }^{17}$ Though statistically insignificant, $\mathrm{T} 2 * \mathrm{CMR}$ values demonstrated a trend of negative correlation 


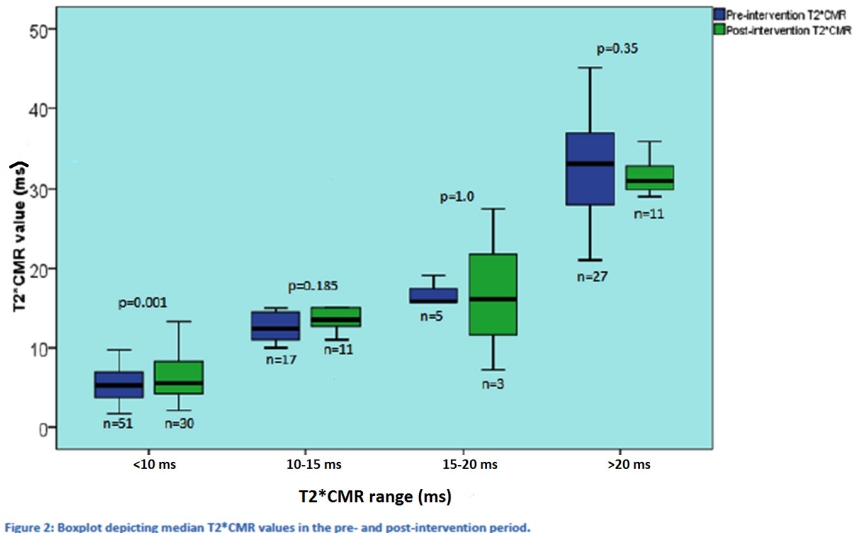

Figure 2 Boxplot depicting median $\mathrm{T} 2{ }^{*} \mathrm{CMR}$ values in the preintervention and postintervention period. $\mathrm{T} 2{ }^{*} \mathrm{CMR}$, cardiac $\mathrm{T} 2$ * magnetic resonance imaging.

with serum ferritin levels $(r=-0.19, p=0.06)$ (online supplemental figure S2). In patients with $\mathrm{T} 2 * \mathrm{CMR}<10 \mathrm{~ms}$ (severe cardiac siderosis), ferritin levels were severely elevated ( $>2500$ $\mathrm{ng} / \mathrm{mL})$ in $49(96 \%)$ patients $(\mathrm{r}=0.847, \mathrm{p}=0.028)$ (online supplemental table S2 and figure S3). Interestingly, 90\% $(n=29 / 32)$ of patients with only mild or no cardiac siderosis (T2*CMR of $>15$ $\mathrm{ms}$ ) had severely elevated ferritin level of $>2500 \mathrm{ng} / \mathrm{mL}$ (online supplemental table S2).

\section{DISCUSSION}

Our study demonstrated the utility of a QI initiative as part of a collaborative to improve management of cardiac iron siderosis in a resource-limited setting where $95 \%$ patients underwent a change in their chelation therapy and majority had improvement in their compliance following this approach. An improvement in cardiac iron overload was seen in $82 \%$ of patients.
Additionally standardising definition and management of drug related AE severity levels prevented inappropriate chelation discontinuation.

In our study, $51 \%$ of patients demonstrated severe cardiac iron overload. This is high compared with several studies that have reported a range of $13 \%-26 \%$ of severe cardiac iron overload in patients with TDT. ${ }^{18-20}$ WHO reports that only $20 \%$ of the patients with TDT in our region may be receiving adequate iron chelation, ${ }^{21}$ while in our study only $5 \%$ patients with TDT were optimally chelated at presentation. The significantly high burden of cardiac iron overload in our setting can be attributed to several key factors including lack of access to healthcare, inappropriate assessment of iron loads, non-standard care, unavailability and unaffordability of chelation medications and non-compliance due to fear of AEs (both by patients and physicians). ${ }^{67}$

We observed that becoming part of a QI collaborative, ${ }^{14}$ and implementation of a QI initiative at the study sites, a large number of patients underwent an increase of chelation (89\%) after initial T2*CMR. This is high compared with a similar study by Akcay et al, ${ }^{22}$ where chelation therapy was changed in only $38 \%$ patients with TDT after T2*CMR assessment. Centres in Pakistan use serum ferritin to assess myocardial iron load and to guide chelation therapy. Lack of correlation of serum ferritin with cardiac siderosis, as depicted in this study and our previous work, ${ }^{9}$ and a non-standard approach to ferritin guided chelation therapy probably are some of the reasons for suboptimal chelation in our population at baseline. Thus the impact of standardising assessment and management of cardiac siderosis using a more reliable and sensitive test like $\mathrm{T} 2 * \mathrm{CMR}$ is quite dramatic in such settings.

Patient compliance to their chelation therapy is pivotal in the management of patients with TDT. Drug affordability, availability, standardised AE management and presence/absence of effective patient counselling are factors that significantly influences patients' compliance with chelation therapy. ${ }^{2324} 25$ Patient

Table 4 Details of expired patients $(n=13)$

\begin{tabular}{|c|c|c|c|c|c|c|c|c|c|c|}
\hline $\begin{array}{l}\text { Case } \\
\text { ID }\end{array}$ & $\begin{array}{l}\text { Age } \\
\text { (years) }\end{array}$ & $\begin{array}{l}\text { Preintervention } \\
\text { T2* CMR value } \\
(\mathrm{ms})^{*}\end{array}$ & Cause of death & $\begin{array}{l}\text { Time to } \\
\text { deatht } \\
\text { (days) }\end{array}$ & $\begin{array}{l}\text { Preintervention } \\
\text { compliance } \\
\text { with chelation }\end{array}$ & $\begin{array}{l}\text { Postintervention } \\
\text { compliance with } \\
\text { chelation }\end{array}$ & $\begin{array}{l}\mathrm{AE} \\
\text { severity } \\
\text { level }\end{array}$ & $\begin{array}{l}\text { Presence } \\
\text { of cardiac } \\
\text { dysfunction on } \\
\text { TTE at baseline }\end{array}$ & $\begin{array}{l}\text { Presence of } \\
\text { arrhythmia } \\
\text { on holter at } \\
\text { baseline‡ }\end{array}$ & $\begin{array}{l}\text { Presence of } \\
\text { pulmonary } \\
\text { hypertension } \\
\text { at baseline }\end{array}$ \\
\hline 1 & 25 & 4.3 & Heart failure & 730 & Partial & Optimal compliance & No $A E$ & Absent & Absent & Present \\
\hline 2 & 13 & 12.3 & Heart failure & 514 & Non-compliant & Optimal compliance & No $A E$ & Absent & Absent & Absent \\
\hline 3 & 23 & 4.5 & Heart failure & 715 & Non-compliant & Optimal compliance & No $A E$ & Absent & Present & Absent \\
\hline 4 & 23 & 2.6 & Arrhythmia (ventricular tachycardia) & 542 & Partial & Optimal compliance & 1 & Present & Present & Absent \\
\hline 5 & 18 & 15.3 & Intracranial bleed secondary to pancytopenia & 472 & Partial & Optimal compliance & No $A E$ & Absent & Absent & Absent \\
\hline 6 & 24 & 6.3 & $\begin{array}{l}\text { Myxedema (cardiomyopathy and anasarca), } \\
\text { infective endocarditis (thromboembolism), sepsis } \\
\text { and heart failure }\end{array}$ & 110 & Non-compliant & Optimal compliance & 1 & Absent & Present & Absent \\
\hline 7 & 11.5 & 4.7 & Intracranial bleed secondary to pancytopenia & 190 & Partial & Optimal compliance & 2 & Absent & Absent & Absent \\
\hline 8 & 19 & 2.6 & Intracardiac thrombus and pulmonary embolism & 97 & Non-compliant & Optimal compliance & 2 & Present & Present & Present \\
\hline 9 & 26 & 9 & $\begin{array}{l}\text { Hepatitis C, severe backache, dyspnoea, chronic } \\
\text { liver disease, ascites, congestive cardiac failure and } \\
\text { massive spleen with varices }\end{array}$ & 257 & $\begin{array}{l}\text { Partial } \\
\text { compliance }\end{array}$ & Optimal compliance & No $A E$ & Present & Absent & Absent \\
\hline 10 & 18 & 3 & $\begin{array}{l}\text { Febrile neutropenia, pain, swelling and bluish } \\
\text { discoloration over knee joint, severe abdominal } \\
\text { pain and dyspnoea }\end{array}$ & 75 & Non-compliant & Optimal compliance & 3 & Absent & Present & Absent \\
\hline 11 & 10 & 33.2 & $\begin{array}{l}\text { Intracranial bleed and sepsis secondary to } \\
\text { pancytopenia }\end{array}$ & 363 & Non-compliant & Partial compliance & No AE & Absent & Absent & Absent \\
\hline 12 & 16 & 11.5 & Intracranial bleed secondary to pancytopenia & 957 & Non-compliant & Partial compliance & 3 & Absent & Absent & Absent \\
\hline 13 & 24 & 5.9 & Intracranial bleed secondary to pancytopenia & 686 & Partial & Optimal compliance & No $A E$ & Absent & Present & Absent \\
\hline
\end{tabular}

*Postintervention $\mathrm{T} 2{ }^{*} \mathrm{CMR}$ was not performed.

tThis is defined as the time to death from the beginning of the intervention. All patients died during the postintervention phase.

$\neq$ Described as sustained and non-sustained atrial and ventricular tachycardia.

$\mathrm{AE}$, adverse events; $\mathrm{T}^{*} \mathrm{CMR}$, cardiac $\mathrm{T2}{ }^{*}$ magnetic resonance imaging; $\mathrm{TTE}$, transthoracic echocardiography. 
education for severity and management of AEs can improve compliance to chelation therapy and their quality of life. By informal estimation, AE resulted in discontinuation (appropriate or inappropriate) of medication in $50 \%$ patients in the preintervention period. This led to building on the experience from the congenital cardiac catheterization laboratory where use of a standard definition of AE severity level has shown to better characterise procedural related $\mathrm{AE}$ and design strategies to mitigate such events. ${ }^{26}$ After introduction and use of our novel chelation drug related AE severity level standard definition and management strategy, no patient had an inappropriate discontinuation of their chelation. This emphasises the need of physician counselling for using these novel AE severity definitions for better characterisation and management of chelation related $\mathrm{AE}$ in thalassaemia treatment centres.

As shown in table 4, six patients died from sepsis and intracranial haemorrhage resulting from pancytopenia due to hypersplenism. This differs from the west where mortality due to cardiac iron overload is the leading cause of death in thalassaemia major. ${ }^{1627}$ One possible reason for this is lack of regular blood transfusions due to unavailability of group specific packed red cells which results in infrequent transfusions in an LMIC setting, persistence of extramedullary haematopoiesis and subsequent hypersplenism. Thus the risk and benefit of early splenectomy in such settings warrants a discussion with the patients and their families.

This study had several strengths and limitations. We report data from LMIC where the burden of disease in terms of cardiac overload in patients with TDT is high due to a non-standard assessment and management strategy. The significant improvement in processes to assess and manage cardiac siderosis and eventual outcome in the form of improving cardiac iron load attest to the need of such a QI initiative and collaborative. Although the duration of a formal evaluation of a QI cycle is typically 3 months, the duration of our QI cycle was 2 years due to reasons described in the methods section. Though we evaluated the process informally and performed reinforcement of compliance with the key driver interventions on a 6-monthly basis, data was not collected and thus not available for a formal analysis. Another limitation was the lack of follow-up of T2*CMR post optimisation in $27 \%$ of patients. This was due to the patient's misconception that continuation of optimal chelation after initial T2*CMR does not warrant a repeat T2*CMR. Patient reported outcomes measures (PROMs) that is, quality of life or NYHA functional class were also not collected and is a significant limitation of this study. Lesson learnt from the first PDSA including training of QI science to physicians at the treating centres, better facilitation of patient follow-up by starting multidisciplinary clinics at the treating centres (like FFK, KITCC etc), reinforcement of getting their investigations on time and obtaining detailed cardiac history including PROMs, NYHA functional class and evaluation for splenectomy if needed are being incorporated into the next cycle. Our novel AE severity level definition needs validation in a larger cohort. The approach to chelation drug dosing and schedule for patient follow-up and assessments, though derived from previously published literature, ${ }^{17}$ were customised to our setting and may need modification in other settings.

In conclusion, this study reveals the feasibility, applicability and effectiveness of a QI initiative and collaborative in a LMIC to improve cardiac morbidity in patients with TDT.

Acknowledgements We thank Dr Waleed Bin Azhar, Chief Operating Officer, Fatimid Foundation, for the support extended to us during this study.
Contributors $\mathrm{SH}$ and $\mathrm{BSH}$ were involved in the overall concept and design of the study. SH, ZH, FA and NA were involved in data analysis and interpretation. EH, $\mathrm{AH}$, $\mathrm{KI}, \mathrm{ZUR}, \mathrm{AQ}$ and AP were included in data collection. BSH performed the final review of the manuscript.

Funding The authors have not declared a specific grant for this research from any funding agency in the public, commercial or not-for-profit sectors.

Competing interests None declared.

Patient consent for publication Not required.

Ethics approval This study was approved by the Fatimid Foundation Ethical Review Committee

Provenance and peer review Not commissioned; externally peer reviewed.

Data availability statement All data relevant to the study are included in the article or uploaded as supplementary information.

ORCID iD

Shabneez Hussain http://orcid.org/0000-0001-8537-7322

\section{REFERENCES}

1 Chen X, Zhang Z, Zhong J, et al. Mri assessment of excess cardiac iron in thalassemia major: when to initiate? J Magn Reson Imaging 2015;42:737-45.

2 Chaudhry-Waterman N, Coombs S, Porras D, et al. Developing tools to measure quality in congenital catheterization and interventions: the congenital cardiac catheterization project on outcomes (C3PO). Methodist Debakey Cardiovasc $J$ 2014;10:63-7

3 Wood JC, Origa R, Agus A, et al. Onset of cardiac iron loading in pediatric patients with thalassemia major. Haematologica 2008;93:917-20.

4 Tanner MA, Galanello R, Dessi C, et al. Combined chelation therapy in thalassemia major for the treatment of severe myocardial siderosis with left ventricular dysfunction. J Cardiovasc Magn Reson 2008; 10:12.

5 Riaz H, Riaz T, Khan MU, et al. Serum ferritin levels, socio-demographic factors and desferrioxamine therapy in multi-transfused thalassemia major patients at a government tertiary care hospital of Karachi, Pakistan. BMC Res Notes 2011;4:287.

6 Trachtenberg FL, Mednick L, Kwiatkowski JL, et al. Beliefs about chelation among thalassemia patients. Health Qual Life Outcomes 2012:10:148.

7 Trachtenberg F, Vichinsky E, Haines D, et al. Iron chelation adherence to deferoxamine and deferasirox in thalassemia. Am J Hematol 2011;86:433-6.

8 Weatherall DJ, Clegg JB. Thalassemia-a global public health problem. Nat Med 1996:2:847-9

9 Alvi N, Tipoo FA, Imran A, et al. Burden of cardiac siderosis in a Thalassemia-Major endemic population: a preliminary report from Pakistan. J Pediatr Hematol Oncol 2016;38:378-83

10 Ali F, Qasim Mehdi M, Akhtar S, et al. Impact of congenital cardiac catheterization project on Outcomes-Quality improvement (C3PO-QI) in LMICs. Heart Asia 2019;11:e011105.

11 Khan $A$, Abdullah A, Ahmad H, et al. Impact of international quality improvement collaborative on congenital heart surgery in Pakistan. Heart 2017;103:1680-6.

12 Hickey PA, Connor JA, Cherian KM, et al. International quality improvement initiatives. Cardiol Young 2017;27:S61-8.

13 Ali F, Rizvi A, Ahmad H, et al. Quality initiative to reduce cardiac CT angiography radiation exposure in patients with congenital heart disease. Pediatr Qual Saf 2019;4:e168.

14 Hoodbhoy Z, Ehsan L, Alvi N, et al. Establishment of a thalassaemia major quality improvement collaborative in Pakistan. Arch Dis Child 2020;105:487-93.

15 Ehsan L, Rashid M, Alvi N, et al. Clinical utility of endocrine markers predicting myocardial siderosis in transfusion dependent thalassemia major. Pediatr Blood Cancer 2018:65:e27285.

16 Borgna-Pignatti C, Cappellini MD, De Stefano P, et al. Survival and complications in thalassemia. Ann N Y Acad Sci 2005:1054:40-7.

17 Veríssimo MPdeA, Loggetto SR, Fabron Junior A, et al. Brazilian thalassemia association protocol for iron chelation therapy in patients under regular transfusion. Rev Bras Hematol Hemoter 2013;35:428-34

18 Anderson $\mathrm{U}$, Holden S, Davis B, et al. Cardiovascular T2-star (T2*) magnetic resonance for the early diagnosis of myocardial iron overload. Eur Heart J 2001:22:2171-9.

19 Au W-Y, Lam WW-M, Chu WWC, et al. A cross-sectional magnetic resonance imaging assessment of organ specific hemosiderosis in 180 thalassemia major patients in Hong Kong. Haematologica 2008;93:784-6.

20 Kwiatkowski JL, Kim H-Y, Thompson AA, et al. Chelation use and iron burden in North American and British thalassemia patients: a report from the thalassemia longitudinal cohort. Blood 2012;119:2746-53.

21 Modell B, Darlison M. Global epidemiology of haemoglobin disorders and derived service indicators. Bull World Health Organ 2008;86:480-7. 


\section{Original research}

22 Akcay A, Salcioglu Z, Oztarhan K, et al. Cardiac T2* MRI assessment in patients with thalassaemia major and its effect on the preference of chelation therapy. Int J Hematol 2014;99:706-13.

23 Viprakasit V, Gattermann N, Lee JW, et al. Geographical variations in current clinical practice on transfusions and iron chelation therapy across various transfusiondependent anaemias. Blood Transfus 2013;11:108-22.

24 Nadeem Ikram KH, Younas M, Amanat S. Ferritin levels in patients of beta thalassaemia major. International Journal of Pathology 2004;2:71-4.
25 Mednick L, Yu S, Trachtenberg F, et al. Symptoms of depression and anxiety in patients with thalassemia: prevalence and correlates in the thalassemia longitudinal cohort. Am J Hematol 2010;85:802-5.

26 Bergersen L, Gauvreau K, Foerster SR, et al. Catheterization for congenital heart disease adjustment for risk method (CHARM). JACC Cardiovasc Interv 2011:4:1037-46.

27 Chouliaras G, Yiannoutsos CT, Berdoukas V, et al. Cardiac related death in thalassaemia major: time trend and risk factors in a large Greek unit. Eur J Haematol 2009;82:381-7. 